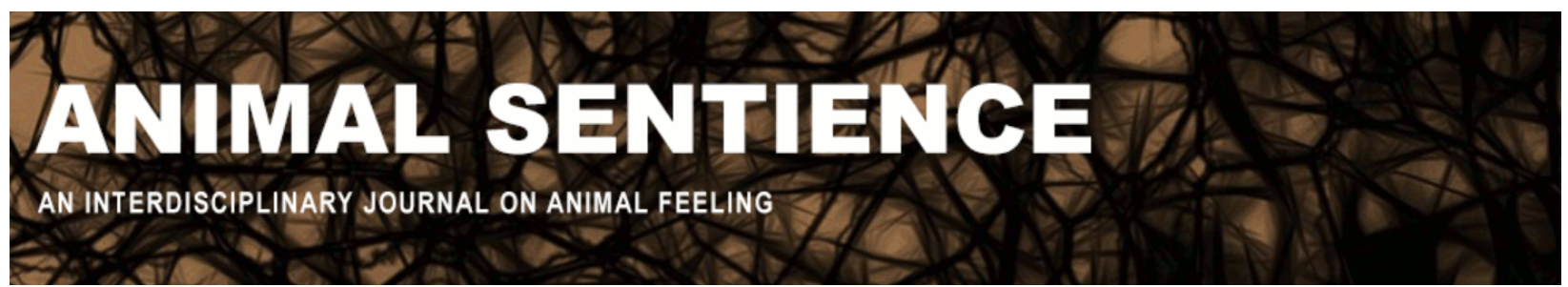

Blumstein, Daniel T. and Lynch, Kate E. (2020) Innovative, yes: But is it rewilding?. Animal Sentience 28(8)

DOI: $10.51291 / 2377-7478.1565$

Date of submission: $2020-03-11$

Date of acceptance: 2020-03-20

(c)

This article has appeared in the journal Animal

Sentience, a peer-reviewed journal on animal

cognition and feeling. It has been made open access,

free for all, by WellBeing International and deposited

in the WBI Studies Repository. For more information,

please contact

wbisr-info@wellbeingintl.org.

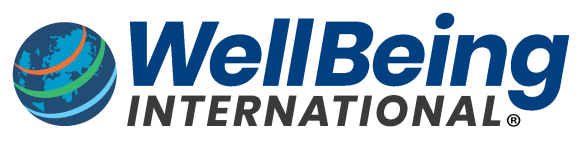

SOLUTIONS FOR PEOPLE, ANIMALS AND ENVIRONMENT 


\title{
Innovative, yes: But is it rewilding?
}

Commentary on Baker \& Winkler on Elephant Rewilding

\author{
Daniel T. Blumstein \\ Department of Ecology and Evolutionary Biology, University of California, Los Angeles
}

\author{
Kate E. Lynch \\ Department of Philosophy and Charles Perkins Centre, University of Sydney
}

\begin{abstract}
Baker \& Winkler's extremely stimulating proposal clearly illustrates conflicting priorities in biodiversity conservation and management that are exacerbated when human cultural resources and animal welfare are a part of the solution. We suggest that the discussion can benefit from an even more explicit unpacking of the conflicting values associated with the proposal.
\end{abstract}

\begin{abstract}
Daniel T. Blumstein is a behavioral biologist and conservation scientist in the Department of Ecology and Evolutionary Biology and the Institute of the Environment and Sustainability at the University of California Los Angeles. His research synthesizes insights from different fields to improve applied outcomes. Website
\end{abstract}

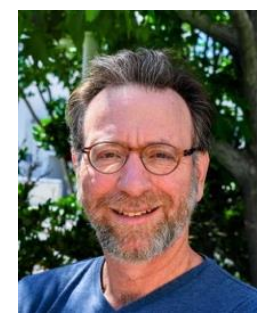

Kate E. Lynch is a philosopher of science and biologist at the Charles Perkins Centre at the University of Sydney. Her current research addresses the most effective ways to implement conservation actions, while taking into account diverse and often conflicting values and interests. Website

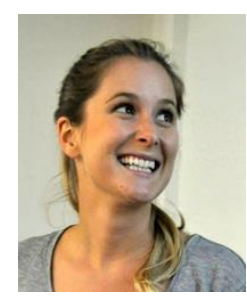

Baker \& Winkler (2020) (B\&W) develop a bold and stimulating proposal to meliorate elephant welfare, protect human cultural practice, and enhance biodiversity. As in ecotourism (Blumstein et al., 2017), there is an attempt to satisfy three distinct objectives - the welfare of wild animals, human interests, and the enhancement or preservation of biodiversity. Trying to satisfy three distinct objectives that are not aligned creates trade-offs that are not always predictable or explicit. Since it is not possible to maximize each criterion, we need to think clearly about the values and goals associated with each, and the most effective ways to achieve them.

Rewilding has an explicitly ecological focus. The success or failure of rewilding should be judged on its ability to maintain species diversity and ecosystem function (Soulé and Noss, 1998; Fernández et al., 2017). In the context of Thai elephants, the species is preserved both in captivity and in the wild. But rewilding a keystone herbivore must also focus on its role in a complex ecosystem, including costs and benefits to other species. Allowing elephants to persist in the wild 
should restore ecosystem function eliminated by their local extirpation. To achieve this, many questions must be answered.

Do we know the historical densities of elephants so that we can set rewilding targets? Do we have enough details about the ecological processes that are to be restored so that we can monitor them? It is unclear where these human-managed elephants will roam. In formerly logged forests? In more pristine forests? If the former, have the ecological and evolutionary goals been clearly laid out? Will elephants enhance biodiversity? If the latter, have the potentially deleterious impacts associated with having humans driving elephants in more pristine forests been considered?

Where humans go, some inevitable deforestation follows along with the introduction of pets, hunting, and other things that might be inconsistent with increasing or even preserving biodiversity. B\&W do suggest that additional research must be done, but as it stands, the proposal really focuses on other aspects of the human-elephant dynamic, potentially at the expense of other conservation values.

A focus on human cultural diversity may have deleterious impacts on biodiversity. Other commentators on the target article have already raised issues concerning meliorating cultural diversity (Kopnina, 2020; Lainé, 2020). We will not do so here other than to point out that bringing people needed to manage elephants into unexploited protected areas will inevitably have a deleterious effect on biodiversity. This may be further exacerbated if the goal is to permit the Karen people to live in more traditional ways in protected forests. While the environmental impact of the Karen people may be far less than that of other human groups, it will nonetheless be more impactful than if there were no human interference. It should be clear that it is difficult to have the same magnitude of benefits for both biodiversity and human cultural diversity. But the proposal has a third criterion - elephant welfare.

The main objective of this proposal is to enhance elephant welfare. This is admirable, but because of the trade-offs we have just discussed, somewhat fraught. If the goal is to improve elephant welfare, B\&W, in their focus on currently living elephants, neglect to consider future generations. We must identify interventions to enhance the integration of rewilded elephants with other captive and wild conspecifics to ensure healthy social dynamics and foster opportunities for breeding. The welfare, and perhaps the existence, of future generations of elephants depends upon a sufficient amount of genetic evolutionary potential, as well as the maintenance of other inheritance channels such as cultural transmission and social learning across generations. This may conflict with retaining a human relationship dynamic such as the one $\mathrm{B} \& \mathrm{~W}$ propose with the Karen people.

Alternatives are not explored. B\&W neglect to ask what it would look like if (1) welfare associated with ecotourism could be improved, (2) the Karen mahout culture could be revived in the context of this improved ecotourism, and (3) some elephants were permitted to live freely in protected forests without the Karen mahouts. Would this be a better solution for all parties involved? Would it meliorate the three objectives of welfare, biodiversity and human interests effectively?

The first step in evaluating effective conservation practice is to clarify the values and objectives involved. There are some clear examples where welfare and conservation interests 
overlap (Freeling and Connell, 2020), but if human interests are included in the mix, conflicting priorities are likely. Assessing the potential consequences of alternatives is an important step in evaluating proposals (Lynch and Blumstein, in review). Baker \& Winkler offer a novel proposal that is sensitive to various interests, but more work is needed to demonstrate that their approach is the most effective alternative for the values and objectives involved.

\section{References}

Baker, L., and Winkler, R. (2020). Asian elephant rescue, rehabilitation and rewilding. Animal Sentience 28(1).

Blumstein, D.T., Geffroy, B., Samia, D.S.M., and Bessa, E. (2017). Introduction: Ecotourism's promise and peril. In Blumstein, D.T., Geffroy, B., Samia, D.S.M., and Bessa, E. (eds.), Ecotourism's promise and peril: A biological evaluation (1-7). Springer Nature.

Fernández, N., Navarro, L.M., and Pereira, H.M. (2017). Rewilding: A call for boosting ecological complexity in conservation. Conservation Letters, 10:276-278.

Freeling, B.S., and Connell, S.D. (2020). Funding conservation through an emerging social movement. Trends in Ecology \& Evolution, 35:3-6.

Kopnina, H. (2020). Of elephants and men. Animal Sentience 28(2).

Lainé, N. (2020). Anthropology and conservation. Animal Sentience 28(5).

Lynch, K.E., and Blumstein, D.T. (In review). Effective conservation. Trends in Ecology \& Evolution.

Soulé, M., and Noss, R. (1998). Rewilding and biodiversity. Complementary goals for continental conservation. Wild Earth, 8:1-11. 


\section{Call for Papers}

Special Issue of the Journal of Consciousness Studies

Plant Sentience: Theoretical and Empirical Issues

Guest Editors: Vicente Raja (Rotman Institute of Philosophy, Western University) Miguel Segundo-Ortin (School of Liberal Arts, University of Wollongong)

In this special issue, we address the issue of plant sentience/consciousness from different disciplines that combine both theoretical and empirical perspectives. Some of the questions to be addressed in the special issue include the following:

- Plants exhibit interesting behaviors; does this entail that they are conscious to some extent?

- What are the requirements for a living organism to be conscious? Do plants meet these requirements?

- What does the possibility of plant sentience/consciousness entail for the study of the evolution of consciousness?

- Is it just a categorical mistake to attribute consciousness to plants?

- Can we talk about different levels or degrees of consciousness?

\section{How to submit?}

Deadline: June 1 1st $^{\text {, } 2020}$

Please submit your papers (max. 9000 words including footnotes, references, abstract, etc.) to vgalian@uwo.ca with subject "Paper Special Issue JCS".

For more information, including bibliography and more detailed descriptions of the topics and questions to be addressed in the papers submitted to the special issue, please contact the guest editors at vgalian@uwo.ca (Vicente) or ms0693@uowmail.edu.au (Miguel). 